\title{
Short research study: determination of risk factors for nightmare. Brief review of the literature, self- experience
}

\begin{abstract}
The author questioned two hundred and two persons of both sexes and of different classes and educational levels. The results of this study determined the risk factors and defined Right-side as a safe position during sleeping. The results were consistent with the Hadith of the prophet Mohamed (Allah's peace be upon him), his advices more than 1430 years ago. During review of literature there were confusions and conflicts of psychologists and psychiatrists concerning criteria, risk factors of nightmare that is why they could not define nightmare. And they could not differentiate between nightmare, night terror and Bad dream too. The author gave a new definition for nightmare and put the main differences between them. The study established the ground work for researchers to studying the enigma of nightmare and other sleep disorders after having new data. This research study was based on, Hadiths of the prophet Mohammed (BPH), review of literature, personal view and self-experience of nightmare dreams.
\end{abstract}

Keywords: hadith, risk factors, right side sleep position, nightmare, bad dream, night terror
Volume I Issue I - 2017

\author{
Othman Alfleesy \\ Department of forensic medicine and pathology, Yemen
}

Correspondence: Othman Alfleesy, Assoc. Prof of forensic medicine, Department of forensic medicine and pathology, Faculty of medicine, Aden University, Yemen, Email alfleesy200I@yahoo.com

Received: May 03, 2017 | Published: June 23, 2017

\section{Introduction}

Sleep is a physiological state, which is not yet clearly understood ${ }^{1}$ other stated: It is a physiological state characterized by a gross reduction in the individual's awareness and responsiveness to his environment. It is readily reversible with diurnal timing and duration. ${ }^{2}$ Sleep disorders as (nightmare, Bad dream), are pathophysiological processes with unknown explanations. No one had determined the risk factors or proposed a perfect definition for this enigma (nightmare) or its risk factors. The word "nightmare" derives from the Old English "mare", a mythological demon or goblin that torments others with frightening dreams. Or referred to a mare a female spirit that was believed to suffocate the sleeping victim. Subsequently, the prefix "night" was added to stress the dream-aspect. The phenomenon of nightmare was described in piles of literature in different societies for a long time. Nightmare is well-known phenomenon since the creation of human being on the earth surface. It may happen to some individuals everywhere in the world. Traditionally this disorder (nightmare) is well known to lay people in the world; each society has its own colloquial term. Nightmare is called (Bangungut) in Philippine, (pokkuri) in Japan. In Arab countries this phenomenon is called gutham or khaboos. It means someone is kneeling on the chest. It is surprising that, in Arabic the verb "gathama" of the noun "Gutham", indicates the suffering of the sleeper from nightmare. The documented stories of sufferers in literatures have thousands of pages and books. It clear that psychiatrists have confusions in regard to its definition, risk factors, associated features. Although the literature is limited regarding etiology of nightmares, the psychiatrists have forwarded a number of definitions, clinical pictures, associated features for nightmares, night terrors, bad dreams and others, but they have failed to hit the target, because lacking of definition and criteria. Despite a number of researches a new view of clear cut study is needed to solve this phenomenon. The author found that, literatures - sometimes- had focused on relationship between nightmares and other dreams as one phenomenon which is totally far from the solution and $100 \%$ against my opinion. By this unique and distinct study the author believes that, it would be a valuable study, to close the gap in this regard. As no previous similar study was found. There is a lack of consensus in the literatures as to whether nightmare is separate, distinct phenomenon or not? ${ }^{3,4}$ Despite a hot debate, it is clear that nightmares have not studied promptly, and It remains unknown in front of all scientists.

\section{What is known about dreams?}

During reviewing literature the following words (terms) were mentioned by many psychiatrists and psychologists, as: Nightmare, bad dreams, sleep terror (night terror) .A dream is the recall of mental activity that has occurred during sleep. ${ }^{5}$ The author puts the following categories of dreams including that of Sunna (Islamic religion).

Ruyaa (true dreams): Mentioned by the prophet Mohammed (BPH) in his Hadith.

The prophet said: True dreams are from Allah and bad dreams are from Satan. This tiding dreams, righteous dreams for prophets and messengers: as the dream of the prophet's Joseph, the son of Jacob, when he dreamed and informed his father Jacob, as stated in holy Qur'an ALLAH says (Of these stories mention) when Joseph said to his father, "O my father, indeed I have seen [in a dream] eleven stars and the sun and the moon; I saw them prostrating to me". Surah joseph (Yusuf) verse 4. 
Good dreams: In this dream, a person may see that he is in a party because he has a success in any Activity or work, or may have a journey with his family...Etc. good news in these dreams.

Hulum (bad dreams): mentioned by the prophet and in literature of psychiatrists which either Bad dreams associated with frightening dreams or with an action, as for example one sees in dream, that he will fall in a well or in a fire..Etc. and may awaken with fear. Or has quarrel or struggle with others or playing football, then he kicks or jumps, Etc. Other Bad dreams may one sees in dream that his father, brother had died, or he sees that one of his relative was ill, or he had injured his hand while cutting a tree, Etc and awaken in the next day normally and stated his dream in sequence storyline with complete, logic content. Dreams which called mixed up false Dreams (in Arabic Ath-Qhath Ahlam) which mentioned in Holy Qur'an.

Allah says (Nay, they say): “These (revelations of the Qur'an which are inspired to Muhammad) are mixed up false dreams! Nay, he has invented it! Nay, he is a poet! Let him then bring us an Ayah (sign as a proof) like the ones Prophets) that were sent before (with signs). (Surah: Al-Anbya.verse-5). These dreams are light dreams illogic, fragmented, meaningless, have no beginning and no end. It may repeat time and time again in a night or in a daytime. Night terror dream, or sleep terror which is related to nightmare only, and it is one of its components, it is a terrifying dream, with a terrible images, fragmented, illogic. You can recall the terrible images only. Lion will attack you, camel will bite you or something is sitting on your chest and you feel suffocation. It is not a separate disorder, psychologists had a misconception in connection to this term as the use it as the same meaning of nightmare or as a phenomenon similar to it. The author suggested linking this term (night terror) to nightmare only as one feature of nightmare, representing the moment of terrifying dream only.

\section{Definitions of nightmares, bad dreams in literature}

The term nightmare has had confused history. Despite psychologists and psychiatrists have many concepts for the term nightmare, but there is still no, complete and perfect definition. The majority of terrifying dreams due to nightmares occur physiologically during REM sleep. ${ }^{6}$ The researchers could not differentiate between nightmares and night terrors and bad dreams. They have not a proper definition, they have not determined the risk factors that trigger nightmare, and they did not know the nature of nightmare or how could this happen? This study is the first one, with no doubt, since studying this enigma (nightmare) has clearly differentiated, with clear demarcating line between: nightmare, night terror and bad dreams. Kramer insisted to consider the dream terror or night terror as a separate issue and nightmare as a failed dream. The other observation is that most psychologists and psychiatrists restricted nightmares occurrence to children as sufferers more than adults which is against my opinion. Anyone having these risk factors may suffer from nightmare, the other point is some psychologists rely on the stories narrated by the children or their parents, while their age not more than 4 years. By reviewing a number of researches the following definitions were included: Nightmares refer to a terrifying terror to some individual in all ages, after having eaten a heavy meal and falling asleep it is a fright reaction during sleep. ${ }^{4}$ The child awakens in terror from a dream usually characterized by feelings of suffocation and helplessness. They are not uncommon and generally occur within an hour or two after going to bed. ${ }^{7}$
Rees stated:" It is an anxiety dream in which something threatens harm to the sleeper. The classical one is associated with helpless paralysis, and happens in the latter half of sleep. ${ }^{8}$ Or it is a terrifying dream which may awake the patient. And commented: Although distinct phenomenological, it is doubtful whether the distinction has any practical significance ${ }^{9 "} \mathrm{Al}-\mathrm{Hafnee}{ }^{1}$ wrote "It is a dream in which the sleeper feels that something is kneeling on the chest".

Lawrence et al. ${ }^{6}$ stated: "In contrast to the frightening dream, the child experiencing nightmare (incubus) cries out while asleep and awakens with the physical expressions of an acute anxiety attack. He or she perspires and breathes heavily. His pupil is usually dilated and his facial expression shows terror. He may complain of tightness or heaviness of his chest. He is, in fact, over breathing. With a frightening dream, the child awakens but is not in acute anxiety or panic attack. If the nightmare is frequently repeated, the child may become fearful of going to bed, they gave sleep paralysis a separate definition, while others consider it as a feature of nightmare ${ }^{6}$ Halliday $^{10}$ suggested that disturbing dreams that awaken the sleeper should be called nightmares, whereas disturbing dreams that do not awaken the sleeper should be called bad dreams.

Aponte $^{4}$ stated: The subject, healthy, young, goes to bed, after having eaten a heavy meals. After he has fallen asleep he is seen to move about in bed in most agitated manner, groaning, yelling and coughing often with frothy fluid exuding from mouth. Attempts to awaken him are unsuccessful, and die within very short time sometimes he is found dead in bed the following morning. ${ }^{4}$ Nightmares are vivid, disturbing, or frightening dreams that cause a startled awakening. Hartman defined a nightmare as a long frightening dream that awaken the sleeper. Irrespective of the waking criterion, nightmares have almost always been defined as frightening dream. Bad dreams are "very disturbing dreams which, though being unpleasant, do not cause the dreamer to awaken". Bad dreams referred by some psychiatrists as "pavor nocturnes", are severe reactions associated with frightened crying out of screaming. The sufferer usually gets out of bed, appears confused and unresponsive and describes an enormous dread. ${ }^{8}$ Night terror Most of researchers and psychologists defined night terror as a sudden arousal accompanied by a feeling of terror. This indicated their confusion to whether it is a separate phenomenon like nightmare or as a feature of nightmare. This supports my opinion that night terror is a component of nightmare, because it is the same term as terrifying dream. The prophet Mohammed (Allah's peace be upon him), deals with this only with few words in his Hadith (good dream and bad dream), and he had never mentioned nightmare in all his Hadith, But, if you will follow his advices you never suffer from nightmare.

\section{The hadith of the prophet}

Narrated Al-Bara' Bin Azib (may Allah be blessed with him) said to me "whenever you go to bed, perform ablution like that for the prayer, lie on your right side and say, O Allah! I surrender to you and entrust all my affairs to you and depend upon your blessings both with hope and fear of you. There is no fleeing from you, and there is no place of protection and safety except with you. O Allah! I believe in your book (The Qur'an) which you have revealed and in your prophet Mohamed (Allah's peace be upon him), whom you have sent. Then if you die on that very night, you will die with faith (i.e. in the religion of Islam). Let the aforesaid words be your last utterance (before sleep). ${ }^{11}$ 


\section{Objectives}

i. To read the Hadith of the prophet Mohamed (Allah's peace be upon him).

ii. To know that lying down on right side position is the safe posture.

iii. To determine the risk factors of nightmare and to define it.

iv. To differentiate between nightmare and bad dream properly.

\section{Materials and methods}

Study was performed on people dwelling in Aden city and countryside. We questioned 202 persons with different educational levels. Their groups include: medical doctors, medical students, technicians, housewives, farmers, military men, secondary school students, nurses... All had been given the same questionnaire which covers: occupation, age, position during sleep, positions that suffered from nightmare, have they eaten dinner before going to bed, have they practiced any activity before sleeping or not, are they had suffered from night terror or nor and what are the differences. Sometimes the explanation of some medical terms was needed for some persons without the so-called leading way. Some persons added their comments either hand writing or orally without asking them. These comments were of benefit to my study and support it.

\section{Results and discussion}

Table 1 shows the total number of individuals questioned are, with the distribution of this number according to different group and sex. The total number is two hundreds two (202). Number of medical students in level $4^{\text {th }}, 5^{\text {th }}$ and $6^{\text {th }}$ was 112 . Forty (40) of this number were males, and 72 females. There number of doctors group was 16 , all were males. Number of other group is (74) which include: military men, housewives, farmers, drivers, technicians, nurses, secondary school students. 40 of them are males, and 34 are females. The ages of these groups range between 20-65 years. Table 2 shows us this number of individuals, their different sleeping positions. The number of right side position was eighty nine, 49 of them were males and 40 were females. Back position (supine) number was fifty three, 23 was males and (30) females. The left side position number was twenty eight, 12 of them were males and 16 were females. Chest abdomen (prone) position number was thirty two persons. 12 were males and 20 were females. The grand total of females is 96 , while males were 106. Table 3 shows the number of sufferers of nightmare in different positions during their sleep, i.e., in their original (first position), before rolling. One female with right sleeping position was suffering from nightmare which might be contradicted our results, but when we came back to ask her and to have details, we surprised when we have known that she is SIDUS VERSUS, which means that the anatomical body organs of the right side were located in the left and vice versa, which means her liver in the left and her heart in the right including other organs. On the back position (supine) there are (7) males sufferers and (5) females the total is (12). On the left side the number of males is (2) and females is (0), so the total is (2). Face-chest position (prone) shows 3 males, and 2 females (total is 5). The total number is (20) including the case of SIDUS VERSUS. Table 4 shows the number of sufferers sleeping on their back after changing the original sides to back only, that means, from right to back, from left to back and from face-chest to back. This gives a total number of (42) including original back position, and indicates those who woke while suffering from nightmares. Table 5 shows the numbers of sufferers in different positions with a total of fifty, (22 males and 28 females). The sole case of right side position is included for statistical value only, but practically means 0 . Table 6 shows us the number of those who suffered from night terrors when they were lying on different sides. The total is seventy four, 21 out of the 74 are sufferers in right side position ( 9 males and 12 females). Table 7A shows the number of those who had eaten their meals (dinners), before going to bed. The total number (177) is distributed between males (101) and females (76) taking into consideration that all who suffered from nightmares are of this group and had had heavy meals. But with a prospective study, we have to put criteria for heavy and light meals, (in spite of that some of them mentioned the type of food), which is necessary for such work as long as we consider a type of food in the predisposing factors. Also some mentioned that it was a heavy Yemeni meal. Table 7B shows the numbers of those who suffered from night terrors whether after eating their dinners or not, which means that there is no relation between food and night terror sufferings. Table 8 shows that the number of sufferers from nightmare had all eaten their meals, while those who do not eat before going to bed never suffer from nightmares: in other words full stomach (heavy) meal is an important trigger for nightmare, i.e. without food and full stomach; there is no nightmare suffering. Table 9 shows total numbers of people who were practicing activities before going to sleep and it is twenty six , (16) males and (10) females. Others who were not practicing activities have a total of (176). Also there this in need for full details in a future study, such as type of activity and time elapsing during practice , but , this will not affect the aim of this work with the current result. Table 10 shows the numbers of those who go to bed within 1-3hrs, is (74), and after more than 3 hours, is (128). All the sufferers of nightmare are in the rank of (1-3hrs), while those who suffered from Bad dreams are from both ranks. Those who suffered from both nightmare and Bad dreams had suffered in two different nights, and the last events were still remembered. The contents of dreams were narrated by a few of them, both males and females as a first step for the author and only for a purpose of recalling dreams or not. It is surprising that those who suffer from nightmare never remember the contents of their dream except the terrible images, while those who have suffered from bad dreams frightening still remember the contents for a long time. This result is in conflict with psychiatrists opinions about the characteristics and definitions for both Bad dream and nightmare. By revision of literature the author have preferred to summarize and expose the most important statements that indicated the conflicts and confusions of scientists, researchers and psychologists in this regard.

Table I Numbers in different groups. Others are Students of lower educational levels, Military men, Housewives, farmers, drivers, technicians

\begin{tabular}{llll}
\hline \multirow{2}{*}{ Group } & Sex & & \multirow{2}{*}{ Total } \\
\cline { 2 - 3 } & Male & Female & \\
\hline Students & 40 & 72 & 112 \\
Doctors & 16 & 0 & 16 \\
Others & 40 & 34 & 74 \\
Total & 96 & 106 & 202
\end{tabular}

\section{Statements of scientists that indicated their confusions}

i. No one determined the causes of nightmare.

ii. The literature is limited regarding the etiology of nightmares. 
iii. Study designs are needed to fully understand the causes and consequences of nightmares.

iv. Research on nightmare has been hampered by inconsistent definition.

v. Hartman said the term nightmare has had a somewhat confused history.

vi. As with many concepts and notions in psychology, there is still no perfect definition of the nightmare.

vii. Consequently, many studies dichotomize nightmares and bad dreams as distinct phenomena.

viii. There is a lack of consensus in the literature as to whether nightmares and bad dreams are, in fact, separate phenomena.

ix. Levin and Nielsen (2009) conceptualized both bad dreams and nightmares together in the same theory.

$\mathrm{x}$. It remains unknown whether they (nightmares and bad dreams) are two qualitatively distinct phenomena or a single phenomenon varying in intensity."

xi. There is a misconception that night terrors and nightmares are the same thing.

xii. Nightmare disorder can be confused with sleep terror. ${ }^{12}$

xiii. What's the difference between sleep terror and nightmare?

xiv. Most commonly we think of nightmares as bad dreams-happen in REM.

xv. The question of what triggers the nightmare remains unclear. Finally, because there is no certainty in their statements and studies, the author forwarded the following definitions.

Table 2 Number of different sleeping Positions

\begin{tabular}{llll}
\hline \multirow{2}{*}{ Position } & Sex & & \multirow{2}{*}{ Total } \\
\cline { 2 - 3 } Right side & M & F & \\
Back & 23 & 40 & 89 \\
Left side & 12 & 16 & 53 \\
Face-chest & 12 & 20 & 32 \\
Total & 96 & 106 & 202 \\
\hline
\end{tabular}

Table 3 Numbers of nightmare's sufferers, in the original sleeping position (before rolling to other position). This number for a female, aged 57 years, housewife with congenital SIDUSVERSUS

\begin{tabular}{llll}
\hline Position of sleeping & Sex & & Total \\
\cline { 2 - 3 } Right side & $\mathbf{M}$ & $\mathbf{F}$ & \\
Back & $1^{*}$ & & 1 \\
Left side & 7 & 5 & 12 \\
Face-chest & 2 & & 2 \\
Total & 3 & 2 & 5 \\
\hline
\end{tabular}

Table 4 Numbers of sufferers in original positions and then rolling to back position

\begin{tabular}{llll}
\hline \multirow{2}{*}{ Sleep position } & \multicolumn{2}{l}{ Sex } & \multicolumn{2}{c}{ Total } \\
\cline { 2 - 3 } & M & F & \\
\hline Right side & 5 & 11 & 16 right/back \\
Back & 7 & 5 & 12 back/back \\
Left side & 3 & 4 & 7 left/back \\
Face-chest & 2 & 5 & 7 face-chest/back \\
Total & 17 & 25 & 42 \\
\hline
\end{tabular}

Table 5 Total numbers of nightmare sufferers. Anatomically this means left (in normal). In other words Right side number is $=0$

\begin{tabular}{|c|c|c|c|}
\hline \multirow{2}{*}{ Sleep position } & \multicolumn{2}{|c|}{ Sex } & \multirow{2}{*}{ Total } \\
\hline & M & $\mathbf{F}$ & \\
\hline Right side & & $1 *$ & 1 \\
\hline Back & 17 & 25 & 42 \\
\hline Left side & 2 & 25 & 2 \\
\hline Face-chest & 3 & 2 & 5 \\
\hline Total & 22 & 50 & 50 \\
\hline
\end{tabular}

Table 6 Number of those who suffered from night terror when lying on different positions. Some of those who suffered night terror took no meal before going to bed

\begin{tabular}{llll}
\hline Sleep Position & Sex & & Total \\
\cline { 2 - 3 } Right side & M & F & \\
Back & 9 & 12 & 21 \\
Left side & 16 & 18 & 34 \\
Face-chest & 2 & 7 & 9 \\
Total & 3 & 7 & 10 \\
\hline
\end{tabular}

Table 7A Number of those who ate their meals (dinner) before going bed.All the sufferers from nightmares had taken their meals

\begin{tabular}{|c|c|c|c|}
\hline \multirow{2}{*}{ Number } & \multicolumn{2}{|l|}{ Sex } & \multirow{2}{*}{ Total } \\
\hline & M & $\mathbf{F}$ & \\
\hline & 101 & 76 & 177 \\
\hline
\end{tabular}

Table 7B The relation between night terrors and food. There is no relation between taking food and suffering from night terror

\begin{tabular}{llll}
\hline & Sex & & Total \\
\cline { 2 - 3 } & M & F & \\
\hline $\begin{array}{l}\text { Number of Those who ate and } \\
\text { suffered from nightmare }\end{array}$ & 22 & 28 & 50 \\
$\begin{array}{l}\text { Number of Those who did not eat and } \\
\text { had no night terror }\end{array}$ & 21 & 4 & 25 \\
Total & 46 & 28 & 74 \\
\hline
\end{tabular}

Table 8 Numbers of those with full stomach and those who did not take their meals. Full stomach probably associated with nightmare empty stomach (hungry, little food) never associated with nightmare

\begin{tabular}{lllll}
\hline & Sex & \multirow{2}{*}{ Total } \\
\cline { 2 - 3 } & M & F & \\
\hline Number of those who suffered after eating & 22 & 28 & 50 \\
No eating, no suffering from nightmare & 21 & 4 & 25
\end{tabular}


Table 9 Number of those who were practicing activities or not before going to bed (after taking dinner). All the sufferers were not practicing activities

\begin{tabular}{llll}
\hline & Sex & & \multirow{2}{*}{ Total } \\
\cline { 2 - 3 } & M & F & \\
\hline Practicing activity & 16 & 10 & 26 \\
Not practicing activity & 80 & 96 & 176
\end{tabular}

Table 10 Number of those who go to their bed within I-3 hrs and more than $3 \mathrm{hrs}$ after taking their meals. All the sufferers from nightmares were from the first rank, while those who suffered from night terror were from both ranks

\begin{tabular}{llll}
\hline \multirow{2}{*}{ Time } & \multicolumn{2}{l}{ Sex } & \multirow{2}{*}{ Total } \\
\cline { 2 - 3 } & $\mathbf{M}$ & $\mathbf{F}$ & \\
\hline 1-3 hrs & 34 & 40 & 74 \\
More than 3 hrs & 62 & 66 & 128
\end{tabular}

Table I I The main differences between Nightmare and Bad dream

\begin{tabular}{ll}
\hline Nightmare & Bad dream \\
\hline $\begin{array}{l}\text { Lying on non- right side } \\
\text { sleeping Position }\end{array}$ & $\begin{array}{l}\text { Any position including Right side } \\
\text { position }\end{array}$ \\
Heavy meal (full stomach). & Heavy meal, or hungry \\
$\begin{array}{l}\text { Sleep paralysis (no limbs } \\
\text { movement). }\end{array}$ & $\begin{array}{l}\text { No paralysis, limb movement, jump } \\
\text { kick }\end{array}$ \\
$\begin{array}{l}\text { Associated with terror dream. } \\
\text { Fragmented, terror images } \\
\text { content have no story to recall. }\end{array}$ & $\begin{array}{l}\text { have a sad dream } \\
\text { complete story. }\end{array}$ \\
$\begin{array}{l}\text { May lead to death. } \\
\text { Associated with suffocation. }\end{array}$ & $\begin{array}{l}\text { No death occurs. } \\
\text { Happen in 1-3 hours after } \\
\text { sleeping. } \\
\text { The sleeper must awaken } \\
\text { sleeping to morning. } \\
\begin{array}{l}\text { May moan (could not open } \\
\text { mouth). } \\
\text { The sufferer awakens in a bad } \\
\text { exhausted status. }\end{array}\end{array}$ \\
$\begin{array}{l}\text { Abrupt arousal by touch } \\
\text { May occur at any time. }\end{array}$ \\
\hline $\begin{array}{l}\text { Its intensity is lesser than and } \\
\text { nightmare. } \\
\text { Awakening may immediate or need } \\
\text { second trial or shouting. }\end{array}$
\end{tabular}

\section{Nightmare}

It is a temporary pathophysiological status represented by terror dream. It may occur (1-3hours) after falling asleep, and having eaten a heavy meal and lying on non-right side sleeping position. It is characterized by suffocation, terrifying dreams (sleep terror), paralysis (could not move limbs). The sleeper could not talk or shout (could not open the mouth), even though trying to do so. May partially awake and feeling of surrounding, moaning (without open mouth). A touch leads to abrupt arousal (touch is the immediate solution to awakening), or by self-arousal chance. If there is no awakening the sufferer is going to die definitely, because there is no other option. Terror dreams are illogical, fragmented, terrifying image. The sleeper remembers the terrifying image only because there is no storyline to recall or be narrated, and this dread image is reflects of suffocation status of the sleeper. When the sleeper have escaped and awakened, it is called (nightmare, Bangungut or Pokkuri in adults and ALTE in infants and small children. ${ }^{13,14}$ If death occurred it is called (SUNDS) $)^{13}$ in adults and (SIDS) in infants. ${ }^{14}$ Nightmare is neither a disease nor psychiatric disorder to be managed by drugs as scientists stated, nor is restricted to creative persons or a useful dream as Hartmann stated.

\section{Bad dream}

It is a frightening dream which may occur to any person, at any time, during sleeping. It has no relation to sleeping positions or heavy meal(full stomach) it could be remembered next day, its content is logic, storyline, the sufferers may shout, jump, kick, and may awaken abruptly, voluntarily because of frightening dream, but not of suffocation (as in nightmare), or may awaken by others help. In contrast to nightmare may you awake while you are speaking, or to ask and speak as a continuation of your frightening or sad dream. This never happens in Nightmare. In bad dream you may have a frightening dream, but in nightmare you must have terror Dream.

\section{Night terror, sleep terror}

Night terror dream, or sleep terror is related to nightmare only. It is one of its components, but not a separate phenomenon as some psychologists stated. It is a terrifying dream, with a terrible images accompanying suffocation status of nightmare sufferer. It is fragmented, illogic, striking image. ${ }^{15}$ You can recall the terrible images only, as lion will attack you, camel will bite you or something is sitting on your chest and you feel suffocation. It is not a separate disorder; there is a misconception by psychologists who use this term as the same meaning of nightmare. The author suggests linking this term (night terror, sleep terror) to be one component (feature) of nightmare, which reflects the suffocation status of the sufferer.

\section{The author has experienced nightmare in his life}

It is the story of my nightmare: One night, before going to sleeping, I have eaten a heavy Yemeni meal (dinner), lying on my back side, and directly I have fallen asleep. After about one hour, I have felt suffocation, stop breathing process (paralytic respiration), limb paralysis (inability to move), I could not shout even trying to do so, I was feeling with the surroundings (partially awake) as a semiconscious, I was moaning (as they told me after), this was going on while the status of suffocation intensity reached its peak (calming storm), definitely I was going to die, and I saw in dream terrifying image, at that critical moment, my wife touched me-to awaken me because the moaning intensity was high-and abruptly I woke up. I was exhausted I have stayed a moment, and oriented quickly, I laughed and as this is known to all it is a nightmare, and returned back to sleep again.

\section{Conclusion}

On the base of the previous data the author have concluded

i. Right side sleeping position is the only safe posture during sleep and this is consistent with the order and advice of the prophet Mohamed (Allah's peace be upon Him) in his Hadith stated for more than 1430 years ago.

ii. This study determines the risk factors of nightmare, gives a new definition for nightmare and bad dreams, and differentiated between them.

iii. The nightmare could be triggering by the combination of: A) Heavy meal. B) Non- right sleeping position. 
iv. Nightmare may lead to nocturnal deaths in adults (SUNDS) and in infants (SIDS).

v. Bad dream may occur in any position including right side position, regardless of full stomach (satisfied) or empty one (hungry).It does not lead to death.

vi. The author wishes to suggest that, those who have the risk factors may suffer from nightmares but you would never find anyone have suffered from nightmares without having these risk factors

vii. Heavy meal.

viii. Non- right sleeping position.

ix. You will never die or others, under the title or mechanism of the so-called "sudden nocturnal death" in adults or infants, when you are lying down on your right side, or helping infants or children to lie on, with heavy or light meal.

x. Nightmares might occur at any age, and every age reflects of 6 expressions during sleep, some end with death (SUNDS-Adults, SIDS-Infants) some escaped death (Nightmare-Adults, ALTEInfants).

xi. Suffocation, terrifying dream and sleep paralysis are main features of nightmare.

xii. In bad dream you might awake with heart pounding and 9 . accelerating heart rate due to frightening dream, but in nightmare you must awake because of asphyxia state (suffocation) and terror images accompanied it.

xiii. The author prefers to link the term (terror dream, night terror, sleep terror) to the nightmare only, because it is a component of nightmare and it must be there.

xiv. The advice of psychologists and psychiatrists: Do not intervene to the sleeper while suffering, is another catastrophic advice like that one for children to sleep prone..$^{14}$ It is mandatory to intervene in order to rescue the sufferer.

xv. Others of no significance: The opinion that to walk while asleep in nightmare and bad dream is not true at all. And the usefulness of nightmare dreams is nonsense. Or nightmare can be caused in children because of watching a scary films, is not correct too. May lead to frightening dreams but not a nightmare.

\section{Acknowledgements}

None.

\section{Conflict of interest}

The author declares no conflict of interest.

\section{References}

1. Al-Hafnee AA. Encyclopedia of psychological analysis (Arabic version). USA; 1995.

Roth T, Roehrs T. An overview of normal sleep and sleep disorders. Eur $J$ Neurol. 2000;(suppl 4):3-8.

3. Nadorff MR, Porter B, Rhoades HM, et al. Bad dream frequency in older adults with generalized anxiety disorder. Behav Sleep Med. 2013;12(1):2840.

Aponte GE. The enigma of bangungut. Ann Intern Med. 1960;52(6):1258 1263.

5. Pagel JF. University of Colorado medical school, Colorado. Am Fam Physician. 2000;61(7):2037-2042.

Lawrence C Kolb, Keith H, et al. Modern Clinical Psychiatry. 10th ed; 1982. p.705-706.

7. Ropert J Campbell. Campbell's psychiatric dictionary. 6th ed. USA: Oxford University Press; 1989.

8. Kendell RF, Zeally AK. Companion to psychiatric studies. 4th ed. USA; 1988.

Lonfort Rees WL. A short text book of psychiatry. 3rd ed. India: 1982. p. 96-73.

10. Halliday G. Nightmare are caused by trauma. Paper presented at the annual meeting of the association for the study of Dreams. USA: Charlottesville VA; 1991.

11. Mohammed MK, Sahih Al-Bukhari. Arabic-English, 1:247.

12. Zadra A, Donderi DC. Nightmares and bad dreams: their prevalence and relationship to well-being. J Abnorm Psychol. 2000;109(2):273-281.

13. Othman Alfleesy. Nightmares (Bangungut) is the leading cause of sudden unexplained nocturnal death among adults (SUNDS), its risk factors, and solution. A review of literature. Global Journal of Medical Research. 2016;16:3.

14. Othman Alfleesy right-side sleeping position prevents sudden infant death syndrome a literature review. Journal of Forensic Science \& Criminology. $4: 2$.

15. Francis Leukel. Introduction to physiological psychology. 3rd ed. USA; 1976. p. 323-325. 